\title{
Research on Enhancing the Effectiveness of Entrepreneurship Education with Entrepreneurship Practice as a Carrier
}

\author{
Xiaokui Wang \\ Sichuan University of Arts and Science, Chengdu, China \\ Email: Pl19800710@163.com
}

How to cite this paper: Wang, X. K. (2020). Research on Enhancing the Effectiveness of Entrepreneurship Education with Entrepreneurship Practice as a Carrier. Creative Education, 11, 275-284. https://doi.org/10.4236/ce.2020.113021

Received: February 5, 2020

Accepted: March 13, 2020

Published: March 16, 2020

Copyright $\odot 2020$ by author(s) and Scientific Research Publishing Inc. This work is licensed under the Creative Commons Attribution International License (CC BY 4.0).

http://creativecommons.org/licenses/by/4.0/

\section{(c) (i) Open Access}

\begin{abstract}
Mass entrepreneurship and innovation is a new engine of economic development, and universities are a gathering and transportation place for talents. It is time to vigorously launch innovation and entrepreneurship education. Entrepreneurship practice is an important part of entrepreneurship education. This article explores the use of entrepreneurship practice as a carrier to improve the effectiveness of entrepreneurship education from four aspects: the transformation of entrepreneurship education concepts, the cultivation of innovative talents, the establishment of entrepreneurship service platforms, and the establishment of entrepreneurship evaluation mechanisms.
\end{abstract}

\section{Keywords}

Entrepreneurship Practice, Entrepreneurship Education, Effectiveness,

Research

\section{Introduction}

In 2020, college graduates will reach 8.74 million, a year-on-year increase of 400,000

(https://baijiahao.baidu.com/s?id=1648919248133136533\&wfr=spider\&for $=$ pc20 20), making it difficult for college students to get jobs. Affected by COVID-19 infections, companies will begin to downsize and lay off employees, which will make college employment face a more complex and severe situation. In order to do a good job of college students' employment and ensure that the employment rate of college students is steadily rising, colleges and universities are paying more and more attention to innovation and entrepreneurship education for college students. Most colleges have set up independent colleges for innovation and 
entrepreneurship education, established college students' innovation and entrepreneurship clubs, and formulated implementation plan for college students' entrepreneurship education, with a view to training college students' innovative and entrepreneurial qualities and improving college students' innovative and entrepreneurial capabilities. The employment report of Chinese college students in 2019 pointed out the situation of self-employment of university graduates. Only $6.2 \%$ of college students still insist on self-employment three years after graduation. The survival rate of entrepreneurship has declined, and the proportion of success has been low. Among them, firstly, the lack of entrepreneurial knowledge and practical experience of college students is the main reason affecting entrepreneurial success. According to this situation, how to carry out effective entrepreneurship education to promote the improvement of entrepreneurial knowledge and practical ability of college students has become the focus of research and attention of the current college education reform and development. Secondly, entrepreneurship practice as an effective extension and enrichment of classroom teaching in entrepreneurship education in colleges and universities has a very pivotal impact on the cultivation of entrepreneurship and the effectiveness of entrepreneurship education in college students. At the same time, it also has a very positive role and significance in realizing the development of the employment market, the integration of university production, study and research, and the promotion of sustainable social and economic development. The following will study strategies for improving the effectiveness of entrepreneurship education in colleges and universities based on the practice of entrepreneurship for reference.

\section{Analysis of the Status Quo of Entrepreneurship Education in Colleges and Universities}

The development of entrepreneurship education in universities is mainly based on the cultivation of innovative and entrepreneurial talents to accelerate the change of employment concepts of college students, improve their employment and entrepreneurship, and meet the needs of talents for local economic construction and development. Based on the current status of entrepreneurship education in colleges and universities, with the increasing importance of entrepreneurship education attached to by colleges and universities, certain innovations and developments have been made in the methods, content, and systems of entrepreneurship education. This has given special significance in the reform and comprehensive development of college education. However, based on the actual situation of entrepreneurship education, there are still many outstanding problems, mainly in the following aspects.

First, the level of attention and significance that colleges and universities attach to the entrepreneurial education is still rather low. With the change in the demand for talents under the socio-economic development coupled with the current severe employment situation in the country, the mode of talent training 
and the method system in the development of college education have also undergone a certain change. However, due to the influence of traditional education concepts and awareness so that at present, in the development of college education, there are still some schools that take the improvement of academic qualifications, reference to civil service exams, and various related vocational qualification certificates as the primary task of student learning. Due to the lack of comprehensive education in entrepreneurship education for students and the severe domestic employment situation. They solely recognize the importance of easing and other aspects, only use entrepreneurship education as a part of college employment guidance, invest less capital and give scant support for entrepreneurship education, coupled with the inadequate assistance of local governments in policy consultation and project selection, technical guidance, risk assessment, and funding guarantee in the development of entrepreneurship education in colleges and universities. These all lead to the general unsatisfactory development and effect of entrepreneurship education in colleges and universities.

Secondly, the combination and connection between entrepreneurship education and professional education in universities is insufficient. Some colleges and universities' entrepreneurship education is at a marginalized position and has not been incorporated into the talent training system. As a result, the combination and connection of entrepreneurship education and professional education in colleges and universities is not close enough, and the curriculum of entrepreneurship education and students' professional courses cannot be effectively connected. Just by adding some teaching courses on entrepreneurship education to the talent training education plan of colleges and universities, the teaching content of entrepreneurship education has less cross-professional and disciplinary links. The teaching time design is also based on the last few semesters of graduation near the students. The course education of students' employment guidance is carried out, and the traditional teacher-based teaching mode is still the main mode. The teaching of entrepreneurship practice is insufficient, resulting in the effectiveness of entrepreneurship education is not obvious.

In addition, the insufficient allocation and utilization of resources in entrepreneurial education in colleges and universities has led to a lack of concerted support for their education development. The effective development of entrepreneurship education in colleges and universities requires not only the establishment of comprehensive education models and teaching systems, but also the continuous innovation of the content and methods of entrepreneurship education to promote the effectiveness of entrepreneurship education. At the same time, it requires government, enterprises, society and other aspects' effective cooperation and support under the guidance of the production-education integration and school-enterprise cooperation education model to realize the development of innovative and entrepreneurial talents required for social development and local economic upgrading. However, according to the actual situation of entrepreneurship education in colleges and universities, while its entrepre- 
neurship education is underway, although the government has issued corresponding support policies for the development of entrepreneurship education in colleges and universities, the publicity of the policy is not in place, causing the lack of understanding in college students of the policy system to encourage entrepreneurship. At the same time, the cooperation of enterprises in the development of college education is mostly expressed as the hope that students can work immediately after graduation. Insufficient knowledge in the cultivation and improvement of students' innovation and entrepreneurship capabilities has led to insufficient student capacity development and exercise, which is not conducive to the long-term and sustainable development of the talent needs of enterprises, which also has a very negative impact on the development of entrepreneurship education in universities.

Third, the practice platform for entrepreneurship education in universities is relatively deficient. A good student entrepreneurship education practice platform is the key to promoting the implementation of entrepreneurship education and the improvement of its educational effectiveness. However, due to the current development of entrepreneurship education in universities, the entrepreneurial education practice platform in some universities is relatively monotonous: The incubation bases exist independently of each other; the construction of interconnected one-stop platforms such as entrepreneurship training, actual combat and entrepreneurial talent training is obviously insufficient; the form of entrepreneurial practice activities for students is relatively single, and the entrepreneurial practice is mostly carried out in the classroom, which is disconnected from the reality of the society. The lack of mutual integration of entrepreneurial knowledge and practical training in entrepreneurship education is very unfavorable to the improvement of the effectiveness of entrepreneurship education in colleges and universities. At the same time, in the university entrepreneurship education, the lack the interaction between the off-campus entrepreneurship practice platform coupled with the low degree of acceptance of some students' entrepreneurial practice activities and short of concerns about the impact on the normal production and economic activities of enterprises all caused insufficient exercise and promotion in practice, which is rather unfavorable to the cultivation and improvement of their entrepreneurial ability.

Finally, another problem facing the entrepreneurial education in colleges and universities is the lack of qualified teachers. The experience and quality of full-time education teachers in entrepreneurship education in colleges and universities are obviously insufficient. Most of the teachers of entrepreneurship education are from teachers who teach employment guidance in colleges and universities. In the development of entrepreneurship education, they not only show less experience in entrepreneurship, but also lack the experience and ability to accurately grasp the national innovation and entrepreneurship policies to provide students with efficient and comprehensive entrepreneurial ability training and promotion assistance in entrepreneurship education, thus resulting in 
poor effectiveness of college entrepreneurship education (Xu, 2011). At the same time, in college entrepreneurship education, the involvement of off-campus mentors in college entrepreneurship education is mostly superficial. It is affected by various factors such as the nature, time, and energy of off-campus mentors. It cannot be used to normalize students in the guidance and teaching of entrepreneurship education. In realizing the innovation and entrepreneurship education of students participating in the whole process, they often provide education and guidance through lectures and other forms, resulting in students not really benefiting, and it is also very unfavorable to the improvement and development of entrepreneurship education.

\section{Main Factors Affecting Entrepreneurship Practice Teaching in College Entrepreneurship Education}

In college entrepreneurship education, entrepreneurship practice teaching itself is a comprehensive teaching discipline. Its teaching development and curriculum design need to target the interaction and interaction between various disciplines based on entrepreneurship and innovative teaching. It should comprehensively design multidisciplinary knowledge of management and psychology, economics, interpersonal communication, sociology, etc., as a supplementary subject of entrepreneurship practice teaching, make breakthroughs and innovations in traditional teaching models, and achieve some unique innovation entrepreneurship activities to promote the quality and effectiveness of entrepreneurship practice teaching. Combining with the actual situation of entrepreneurship practice teaching in college entrepreneurship education, the article concludes that the factors that affect entrepreneurship teaching mainly include the subjective factors of entrepreneurial practice participants and objective factors such as the practice environment.

In the practice teaching and activities of entrepreneurship, participants' basic qualities such as entrepreneurial consciousness, entrepreneurial psychological quality, entrepreneurial spirit, competition awareness, and entrepreneurial ability (https://zhidao.baidu.com/question/1859947680075644547.html2020) have an important influence on the effectiveness of entrepreneurial practice activities. In the development of entrepreneurship education in colleges and universities, students, as important participants in the teaching and activities of entrepreneurship practice, have not matured their psychological qualities, or have shown high enthusiasm and sufficient confidence in the prospect of entrepreneurship in the early stage of entrepreneurship practice activities. The difficulties and problems in the entrepreneurial process are underestimated, leading to their lack of patience and perseverance when faced with failure or setbacks. This will further find embodiment in that their entrepreneurial enthusiasm and self-confidence will be frustrated, which will also have a corresponding adverse impact on the effectiveness of entrepreneurship.

The impact of objective factors such as the entrepreneurial environment and atmosphere on the effectiveness of entrepreneurial practice is reflected in the 
fact that a good entrepreneurial practice environment requires not only the cooperation of the state, society, schools, and enterprises, but also the establishment of a sound and complete entrepreneurial practice education guarantee system in the country. The university's entrepreneurship practice education need to provide certain funds, personnel and social resources to support students who adhere to the entrepreneurship practice. We need to create a social culture featuring innovation, form a pluralistic, inclusive and open innovation cultural environment, and advocate a culture of innovation that embraces adventure, courage to innovate, tolerance for failure, pursuit of success, openness, tolerance, competition, passion, and impetuousness (Jiao, 2011). Through the creation of typical entrepreneurial demonstration images and publicity to drive influence, it is necessary to establish a good cooperative relationship with off-campus enterprises and a corresponding entrepreneurship practice education platform to promote the promotion of college entrepreneurship education and entrepreneurship practice.

\section{Research on the Strategy of Enhancing the Effectiveness of Entrepreneurship Education in Universities Based on Entrepreneurship Practice}

\subsection{Cases and Methods of Promoting Entrepreneurship Education in Colleges and Universities by Taking Entrepreneurship Practice as a Carrier}

Undertaking entrepreneurship education in colleges and universities is an educational activity carried out to expand and extend traditional employment education to meet the requirements of innovative and entrepreneurial talents required for social and economic construction and development under the increasingly severe employment situation of college students. Combining the development of entrepreneurship education in colleges and universities, in the implementation of entrepreneurship education in colleges and universities based on entrepreneurship practice, it is necessary to strengthen the guiding role of entrepreneurship topics and projects and entrepreneurial practice activities, and at the same time to strengthen the cultivation of students' autonomous learning ability. Through the integration and application of innovation and creativity, entrepreneurial ideas and methods in entrepreneurial practice, a comprehensive and comprehensive entrepreneurial practice model can be established to achieve the cultivation and improvement of students' entrepreneurial knowledge and entrepreneurial practice ability. As shown in Figure 1, the " $3+2$ " entrepreneurial practice model constructed in the entrepreneurial education of a university with entrepreneurial practice as a carrier has played a very active role and significance in the promotion and development of its entrepreneurial education.

The " $3+2$ " entrepreneurial practice model shown above includes three platforms and two evaluation systems. Among them, the three platforms in the entrepreneurial practice model have different performances in terms of practical training in achieving students' entrepreneurial qualities. Among them, the 


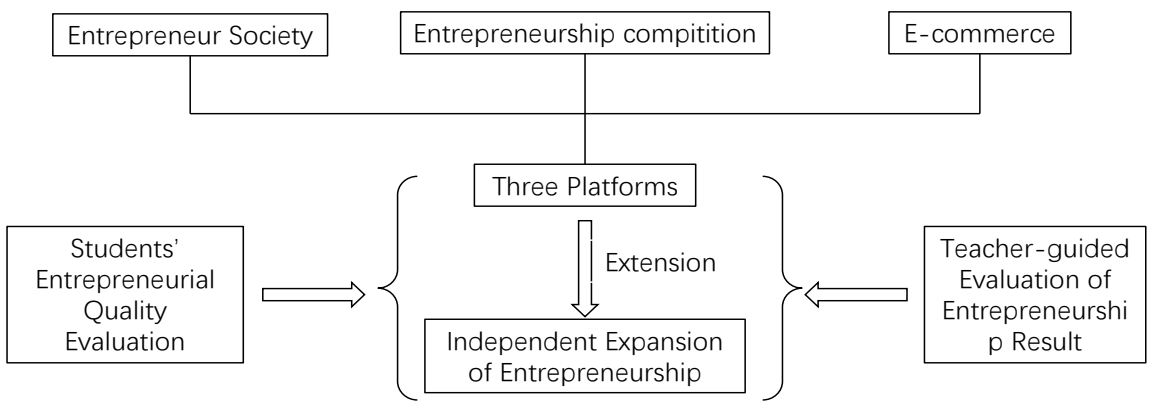

Figure 1. “ $3+2$ " Entrepreneurship practice model in universities.

entrepreneurial community focuses on the cultivation of students' entrepreneurial mentality, the entrepreneurial competition on the training of entrepreneurial knowledge accumulation, and the e-commerce business on the organization and management of students' entrepreneurial activities and the cultivation and improvement of social abilities. The three platforms are used as the basis for educational activities to make good choices in entrepreneurship projects and encourage students to independently expand the content and scope of entrepreneurship, thus strengthening the training of students' entrepreneurship practice. At the same time, the evaluation of the entrepreneurial quality of middle school students and the evaluation of the effect of teacher guidance on entrepreneurship should always be carried out in the practice of entrepreneurship, which is conducive to the effective development of entrepreneurship practice and the improvement of actual effectiveness.

In addition, in entrepreneurship education in colleges and universities, the entrepreneurial practice training for students includes both training and improvement of students' professional knowledge and skills, as well as the accumulation and training of entrepreneurial practical experience so that students can participate in the production and business of enterprises. After participating in the entire process of enterprise production and operation management, students understand the risks of market operations in order to make reasonable predictions of market changes, so as to achieve effective market information grasp, and continuously improve their comprehensive interpersonal and social activities ability to lay a good foundation for the implementation of innovation and entrepreneurship. It should be noted that, in entrepreneurship education in colleges and universities, combined with the development of entrepreneurship practice activities, in the realization of education aimed at the cultivation of students' entrepreneurial psychological ability and market research and development ability, business management, teamwork and other capabilities, the realization of entrepreneurial practice and the process of entrepreneurship education as a carrier and its main content are shown in Figure 2.

\subsection{Strategies for Enhancing the Effectiveness of Entrepreneurship Education by Taking the Practice of Entrepreneurship as the Carrier}

First of all, we must strengthen the transformation and improvement of the 


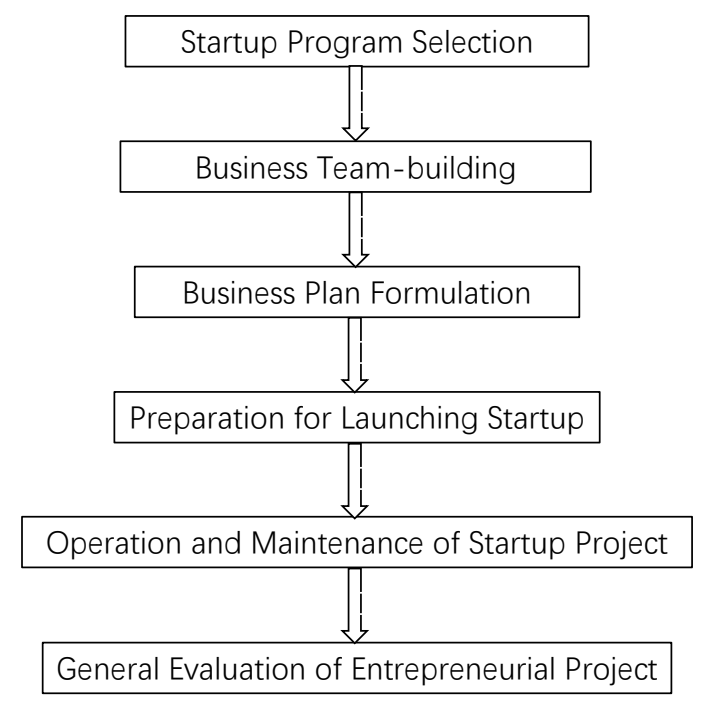

Figure 2. Entrepreneurship Education Process and Content Based on Entrepreneurial Practice.

concept of entrepreneurship education and continue to stimulate and enhance students' entrepreneurship and boost their enthusiasm of participating in practical activities to achieve the cultivation and improvement of students' autonomous learning and practical ability, thereby promoting the effectiveness of entrepreneurship education in colleges and universities. With the development of society and economy, in the development of college education, in order to meet the requirements of talent training goals required for social and economic development, it is necessary to continuously change its educational development thinking, increase the emphasis on entrepreneurship education, and promote the transformation of college education concepts so as to achieve the establishment of knowledge-based and ability-oriented new talent training and education model and continue to explore and innovate the mode and evaluation mechanism of entrepreneurial practice activities in colleges and universities, promoting the effectiveness of entrepreneurship practice activities and the effectiveness of college entrepreneurship education. On the other hand, for college students, college students need to combine their own professional characteristics to enhance their awareness of self-employment thinking and continuously improve their entrepreneurial development. They should clarify the direction of entrepreneurship and establish good entrepreneurial confidence. They should also actively participate in the school's entrepreneurial practice activities, continuously train and improve their social knowledge and entrepreneurial practice ability in order to lay a solid foundation for the development of independent entrepreneurship.

Secondly, In addition, in the improvement of the effectiveness of entrepreneurship education in colleges and universities based on entrepreneurship practice, it is also necessary to strengthen the establishment of organizational coordination relationships in entrepreneurship practice, create a service platform for 
entrepreneurship guidance, enhance the entrepreneurial experience of college students, and improve the success rate of entrepreneurship (Huang \& Li, 2011). The innovation and development of college education needs to start from the scientific positioning of achieving the goal of cultivating innovative and entrepreneurial talents, and according to the students' needs for entrepreneurial expertise, the corresponding curriculum system should be constructed from the aspects of entrepreneurial knowledge, entrepreneurial spirit, entrepreneurial skills, and innovative ability training. It is also a prerequisite to continue to improve and perfect the content of entrepreneurship education courses in colleges and universities in terms of the full integration and effective penetration and continuous strengthening of education development, and strengthen the collaborative development of teaching in various disciplines with entrepreneurship practice as a carrier, and promote the establishment of diversified training models for college entrepreneurship education in order to promote the innovation and improvement of its education reform and development and talent training model.

In addition, in the improvement of the effectiveness of entrepreneurship education in colleges and universities based on entrepreneurship practice, it is also necessary to strengthen the establishment of organizational and coordination relationships in entrepreneurship practice, and to continuously improve the effectiveness of entrepreneurship education through continuous construction and improvement of the university entrepreneurship guidance service platform. In the development of entrepreneurship education in colleges and universities, the establishment of entrepreneurship guidance service platforms is an important operating mechanism to realize the organization and guidance services for entrepreneurship practice activities of college students. The establishment of entrepreneurship education based on entrepreneurship practices requires the establishment of college entrepreneurship service guidance platforms. The development of various entrepreneurial guidance seminars will promote the exchange of entrepreneurial practice experience and realize various forms of entrepreneurial practice students, thus guiding students to actively participate in it, and to effectively guide them to solve different problems they encountered in implementing their entrepreneurial practice activities. At the same time, the communicative function of the entrepreneurship guidance service platform should be used to coordinate the relationship between schools, enterprises, and society to create a good entrepreneurial practice environment and atmosphere, promoting the effectiveness of entrepreneurship education.

Finally, in carrying out entrepreneurship education based on entrepreneurial practice, it is also necessary to promote the quality of education through the establishment of incentive policies and guarantee measures, the establishment of a scientific and complete entrepreneurial education effectiveness evaluation system, and a good entrepreneurial education environment. Among them, the establishment of a scientific and comprehensive evaluation system for the effec- 
tiveness of entrepreneurship education needs to correlate the effects of entrepreneurship practice with student credits, their comprehensive evaluation, employment recommendation, priority training, and funding subsidies to achieve the cultivation of student entrepreneurship initiative and autonomy. At the same time, it is necessary to establish corresponding reward systems and measures, integrate reasonable evaluation standards and promotion systems, and implement the incentive mechanism of superiority and inferiority to make outstanding mentors stand out (Li, 2017). We need also to encourage and guide entrepreneurial tutors to provide comprehensive skills and experience assistance to the team in entrepreneurship education and achieve the establishment of a team of high-quality entrepreneurship instructors. Colleges and universities should establish corresponding student entrepreneurship special support funds, do a good job of coordinating cooperation between students and business units, reasonably open the school's public resources, and provide students with good environmental support for their independent entrepreneurship and entrepreneurship education.

\section{Conclusion}

The task of higher education is to cultivate high-level professionals with innovative spirit and practical ability. Carrying out entrepreneurship education in colleges and universities is of great significance for advancing the construction of an innovative country, promoting the transformation of scientific and technological achievements, deepening the reform of higher education, cultivating students' innovative spirit and practical ability, implementing employment with entrepreneurship, and promoting the self-development of college students.

\section{Conflicts of Interest}

The author declares no conflicts of interest regarding the publication of this paper.

\section{References}

8.74 Million! The Number of College Graduates in 2020 Reached a New Record, an Increase of 400,000 .

https://baijiahao.baidu.com/s?id=1648919248133136533\&wfr=spider\&for=pc2020

Huang, H. Y., \& Li, Y. B. (2011). Creating a Practical Platform for Entrepreneurship Education Improving Entrepreneurial Success Rate. Journal of Human Environment-Biological Polytechnic, 16, 57-60.

Jiao, H. (2011). Study on Business Problem Faced by College Students. Journal of Liaoning Police Academy, 69, 108-111.

Li, S. (2017). Discussion on the Construction of Innovation and Entrepreneurship Mentor Team. Education Modernization, 10, 20-21.

What Qualities Entrepreneurs Need. https://zhidao.baidu.com/question/1859947680075644547.html2020

Xu, S. Y. (2011). Research on the Status, Problems and Paths of Entrepreneurship Education in Independent Colleges of Finance and Economics. Journal of Taiyuan Urban Vocational College, 6, 75-76. 